\title{
Tragic deaths by choking in healthy children
}

Hong Kong Med J 2019;25:413

https://doi.org/10.12809/hkmj197998

To the Editor-In February 2019, local news in Hong Kong reported a 12-year-old boy died 3 days after choking on a beef ball. ${ }^{1}$ The boy bought some food after school and choked on a piece of beef ball he was eating while walking home. Reportedly, he could not breathe nor cry for help, but a security guard saw him clutching at his neck. She called the police as the boy collapsed. He was transferred to an intensive care unit, where he later died from hypoxic brain damage which led to multi-organ failure.

There were two similar incidents in 2018 in Hong Kong. In January, an 8-year-old girl choked on a cuttlefish ball bought at a school kiosk during recess and died after 26 days in hospital. In March, a 2 -year-old girl died after choking on a grape at home. Reportedly, the girl could not breath and fell into a coma. Her father had slapped her back but failed to dislodge the object.

Ingestion-associated adverse events can arise from many different scenarios and may result in mortality and high morbidity. ${ }^{2-5}$ We have previously reported that these children are usually healthy, and that all age-groups can be affected. ${ }^{2,3}$ Solids are usually associated with symptoms from local obstruction or suffocation, whereas fluids may be associated with systemic manifestations and anaphylaxis. Presentations are generally acute, dramatic, and unmistakable. The majority of patients made a prompt and uneventful recovery and had only a short stay in an intensive care unit, especially if emergency care was promptly provided.

The tragic cases unfortunately often occur in previously healthy children. Although prevention is feasible (not eating while talking and walking), choking and suffocation are eminently treatable by a simple manoeuvre. People who see the unmistakable neck-clutching sign of choking can help by performing the Heimlich manoeuvre. To perform this, stand behind the individual in distress, make a fist, position it over the stomach of the individual, and pull sharply inward and upward on the abdomen until the object is ejected. The 2019 case illustrates that this simple life-saving procedure was not available in a timely manner. There is a lot of room for public education.

Effective strategies in the prevention of choking should include cultivating/developing the habit of not eating while talking and walking at individual, family, and public health levels. Studies have shown that children aged $<3$ years remain at greatest risk of food injury and death. Hard, round foods with high elasticity or lubricity properties, or both, pose a significant level of risk. ${ }^{6,7}$ Awareness of the key characteristics of the most hazardous foods may greatly decrease risks of airway obstruction injuries.
Food safety education can help paediatricians and parents select, process, and supervise appropriate foods for children aged $<3$ years.

The possibility of engaging the public, especially those with jobs that bring them into contact with the public, such as security personnel, public transport workers, restaurant staff, school teachers, as well as parents and senior high school students, to learn basic first aid, external cardiac message, use of automated external defibrillator, and the Heimlich manoeuvre should be promoted. After all, the Heimlich manoeuvre is a simple life-saving procedure that is easy to master. ${ }^{8}$

\section{Author contributions}

All authors contributed to the concept, drafting of the article, and critical revision for important intellectual content.

\section{Conflicts of interest}

All authors declared no conflicts of interest.

1,2 KL Hon *, MB, BS, MD

${ }^{1}$ Albert SW Ku, MB, BS, MRCP

1 Department of Paediatrics and Adolescent Medicine, Hong Kong Children's Hospital, Kowloon Bay, Hong Kong

${ }^{2}$ Department of Paediatrics, The Chinese University of Hong Kong, Shatin, New Territories, Hong Kong

*Corresponding author: ehon@hotmail.com

\section{References}

1. Boy, 12, dies three days after choking on beef ball. The Standard 2019 Feb 25. Available from: http://www. thestandard.com.hk/section-news.php?id=205303. Accessed 25 Feb 2019.

2. Hon KL, Leung TF, Hung CW, Cheung KL, Leung AK. Ingestion-associated adverse events necessitating pediatric ICU admissions. Indian J Pediatr 2009;76:283-6.

3. Hon KL, Leung TF, Cheung KL, et al. Severe childhood injuries and poisoning in a densely populated city: where do they occur and what type? J Crit Care 2010;25:175. e7-12.

4. Hon KL, Leung AK. Childhood accidents: injuries and poisoning. Adv Pediatr 2010;57:33-62.

5. Hon KL, Chu WC, Sung JK. Retropharyngeal abscess in a young child due to ingestion of eel vertebrae. Pediatr Emerg Care 2010;26:439-41.

6. Wu X, Wu L, Chen Z, Zhou Y. Fatal choking in infants and children treated in a pediatric intensive care unit: a 7-year experience. Int J Pediatr Otorhinolaryngol 2018;110:67-9.

7. Altkorn R, Chen X, Milkovich S, et al. Fatal and nonfatal food injuries among children (aged 0-14 years). Int J Pediatr Otorhinolaryngol 2008;72:1041-6.

8. Ekberg O, Feinberg M. Clinical and demographic data in 75 patients with near-fatal choking episodes. Dysphagia 1992;7:205-8. 